\title{
A NON-UNIQUENESS THEOREM IN THE THEORY OF VORONOI SETS
}

\author{
M. JONES \\ Department of Pure Mathematics \\ Queen's University \\ Belfast BT 7 inN \\ Northern Ireland \\ (Received March 14, 1990)
}

ABSTRACT. It is shown that two distinct, bounded, open subsets of $\mathbb{R}^{2}$ may possess the same Voronoi set.

.KEY WORDS AND PHRASES. Voronoi set.

1980 AMS SUBJEC' CLASSIFICATION CODES. 51M15, $51 \mathrm{KO}$.

\section{INTRODUC'TION}

Let $\left\{D_{i}\right\}_{0 \leq i \leq n}$ be a finite collection of non-empty, bounded, open and simply connected subsets of $\mathbb{R}^{2}$ which satisfy $D_{i} \subset D_{0}, D_{i} \neq D_{0}, 1 \leq i \leq n$ and $D_{i} \cap D_{j}=\emptyset$, $1 \leq \mathrm{i}<\mathrm{j} \leq \mathrm{n}$. Then if we define $\Omega=\mathrm{D}_{0} \backslash \underset{\mathrm{i}=1}{\mathrm{u}} \overline{\mathrm{D}}_{\mathrm{i}}, \Omega$ is a non-empty, bounded, open and connected subset of $\mathbb{R}^{2}$ with boundary $\partial \Omega=\underset{i=0}{\mathrm{n}} \partial \mathrm{D}_{i}$. (Loosely speaking, $\Omega$ is a domain $\mathrm{D}_{0}$ containing "obstacles" $\mathrm{D}_{i}, 1 \leq \mathrm{i} \leq \mathrm{n}$. ) The the following definition of the Voronoi diagram $\operatorname{Vor}(\Omega)$ of $\Omega$ is taken from [1].

For any $(x, y) \in \Omega$, define $\operatorname{Near}(x, y)$ as the set of points in $\partial \Omega$ closest to $(x, y)$. ("Closest to" is, of course, defined in terms of ordinary Euçlidean distance in the plane.) Since $\partial \Omega$ is closed, Near $(x, y)$ is always non-empty.

The Vuronvi diagram $\operatorname{Vor}(\Omega)$ of $\Omega$ is then defined to be the set of points

$$
\{(x, y) \in \Omega: N e a r(x, y) \text { contains more than one point }\} .
$$

$\operatorname{Vor}(\Omega)$ is used in [l] in connection with motion planning problems.

Clearly given the sets $\left\{D_{i}\right\}, \operatorname{Vor}(\Omega)$ is unique. However, here we take the opposite point of view and consider the construction of the sets $\left\{D_{i}\right\}$ from a given Voronoi diagram.

A preliminary question that one might ask is: could it be possible for two collections $\left\{D_{i}\right\}$ and $\left\{D_{i}^{\prime}\right\}$ to have the same Voronoi diagrams? It is easy to see that the answer is yes: for $0<\varepsilon<1$ let

$$
\begin{aligned}
& D_{0}^{\varepsilon}=\left\{(x, y) \mid x^{2}+y^{2}<(1+\varepsilon)^{2}\right\} \quad \text { and } \\
& D_{1}^{\varepsilon}=\left\{(x, y) \mid x^{2}+y^{2}<(1-\varepsilon)^{2}\right\} .
\end{aligned}
$$


Then if $\Omega^{\varepsilon}=\mathrm{D}_{0} \backslash \overline{\mathrm{D}}_{1}, \operatorname{Vor}\left(\Omega^{\varepsilon}\right)$ is the unit circle, centre the origin, whatever the value of $\varepsilon$ inight be.

A more subtle question is the following: Suppose $D_{0}=D_{0}^{\prime}$, then is it possible for two different collections $\left\{D_{i}\right\}$ and $\left\{D_{i}^{\prime}\right\}$ to have the same Voronoi diagram? Informally, what we are asking is whether, given a fixed domain $D_{0}$, it is possible to arrange two different sets of obstacles within $\mathrm{D}_{0}$, both of which produce the same Voronoi diagram.) We show the answer is again in the affirmative.

2. THE EXAMPLE

Let

$$
\begin{aligned}
& \mathrm{D}_{0}=\{(\mathrm{x}, \mathrm{y})|| \mathrm{x}|<4,| \mathrm{y} \mid<4\} \\
& \mathrm{D}_{1}=\{(\mathrm{x}, \mathrm{y})|| \mathrm{x} \mid<3,1<\mathrm{y}<3\} \\
& \mathrm{D}_{2}=\{(\mathrm{x}, \mathrm{y})|| \mathrm{x} \mid<3,-3<\mathrm{y}<-1\} .
\end{aligned}
$$

Then $\Omega$ and $\operatorname{Vor}(\Omega)$ (where $\Omega=\mathrm{D}_{0} \backslash \overline{\mathrm{D}}_{1} \cup \overline{\mathrm{D}}_{2}$ ) are depicted in Figure 1. Note in particular that $\operatorname{Vor}(\Omega)$ contains the 1 ine segment $\{(x, 0)|| x \mid \leq 1\}$.

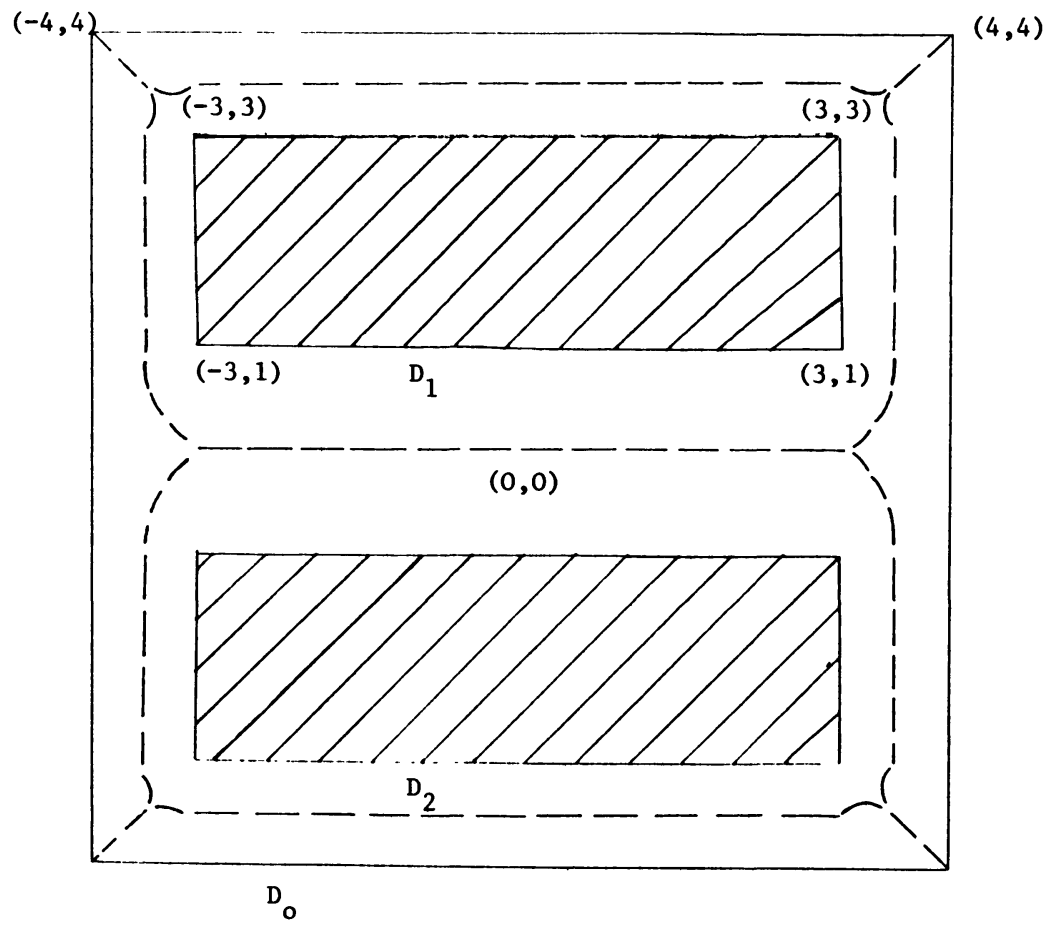

Figure 1 - Vor $(\Omega)$ is denoted by the dashed 1 ine 
We wodify $\mathrm{D}_{1}$ and $\mathrm{D}_{2}$ as follows.

Let $\mathrm{C}=\left\{(\mathrm{x}, \mathrm{y}) \mid \mathrm{x}^{2}+\mathrm{y}^{2} \leq 2\right\}$ and put $\mathrm{D}_{1}^{\prime}=\mathrm{D}_{1} \backslash \mathrm{C}, \mathrm{D}_{2}^{\prime}=\mathrm{D}_{2} \backslash \mathrm{C}$. Then if $\Omega^{\prime}=\mathrm{D}_{0} \backslash \overline{\mathrm{D}}_{1}^{\prime} \cup \overline{\mathrm{D}}_{2}^{\prime}$, $\operatorname{Vor}(\Omega)=\operatorname{Vor}\left(\Omega^{\prime}\right)$, (see Figure 2$)$.

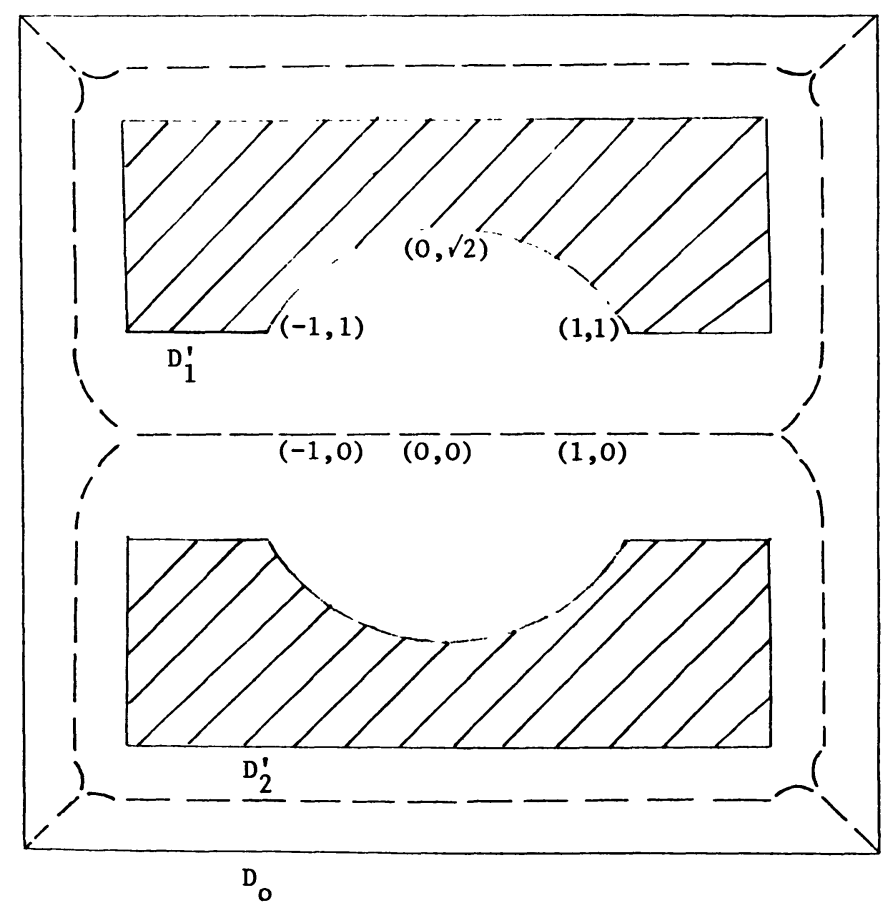

Figure 2 - Vor $\left(\Omega^{\prime}\right)$ is denoted by the ashed line

To see that the Voronoi diagrams of $\Omega$ and $\Omega^{\prime}$ are indeed the same first note that it suffices to consider those points $(x, y)$ in $\Omega^{\prime}$ for which $|x| \leq 1$ and $|y| \leq \sqrt{ } 2$ since for any other $(x, y) \in \Omega^{\prime}$, Near $(x, y)$ will be unchanged by the modifications made to $\mathrm{D}_{1}$ and $\mathrm{D}_{2}$. To begin with, consider those points within the triangle whose vertices are $(-1,0),(0,0)$ and $(-1,1)$. It is clear that if $(x, y)$ is such a point then $\operatorname{Near}(x, y)=\{(-1,1)\}$ and so $(x, y) \notin \Omega^{\prime}$. The same conclusion is true for the points in $\Omega^{\prime}$ which lie on the straight lines joining $(-1,1)$ to $(-1,0)$ and $(-1,1)$ to $(0,0)$, (excluding the endpoints of those lines). Next consider the points $(x, 0)$ where $-1 \leq x<0$. For such a point $\operatorname{Near}(x, 0)=\{(-1,1),(-1,-1)\}$ and so $(x, 0) \epsilon \operatorname{Vor}\left(\Omega^{\prime}\right)$. It is also clear that $(0,0) \epsilon \operatorname{Vor}\left(\Omega^{\prime}\right)$. Now consider those points within the sector of $\mathrm{C}$ which has vertices $(0,0),(-1,1)$ and $(0, \sqrt{2})$. If $(x, y)$ is such a point then it is easy to see that Near $(x, y)$ consists of the single point obtained by projecting the straight line joining $(0,0)$ to $(x, y)$ until it intersects $D_{1}^{\prime}$. The same conclusion is true for the points on the straight line between $(0,0)$ and $(0, \sqrt{2})$ (excluding the endpoints of course). The results for 
the remaining points in $\Omega^{\prime}$ follow immediately from the symmetry of $\Omega^{\prime}$. Hence $\operatorname{Vor}(\Omega)=\operatorname{Vor}\left(\Omega^{\prime}\right)$.

A possible weakness of this example is that the sets $D_{1}^{\prime}$ and $D_{2}^{\prime}$ are not convex. The answer to the same question as that posed in $\$ 1$ but with the additional hypothesis that all the sets in $\left\{D_{i}\right\}$ and $\left\{D_{i}^{i}\right\}$ be convex would appear to be unknown.

\section{REFERENCES}

1. O'DÚNLAING, C. and YAP, C.K., A 'retraction'method for planning the motion of a disc, J. of Algorithms, 28 (1985), 104-i11. 


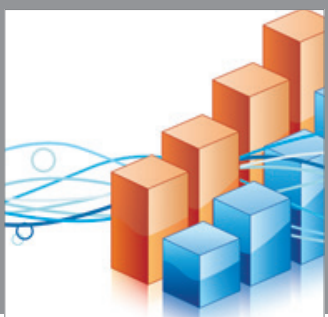

Advances in

Operations Research

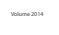

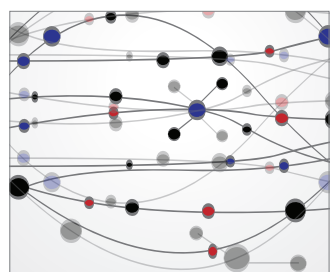

\section{The Scientific} World Journal
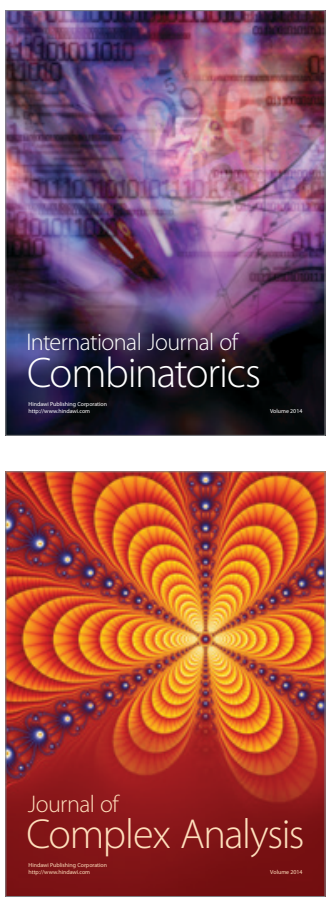

International Journal of

Mathematics and

Mathematical

Sciences
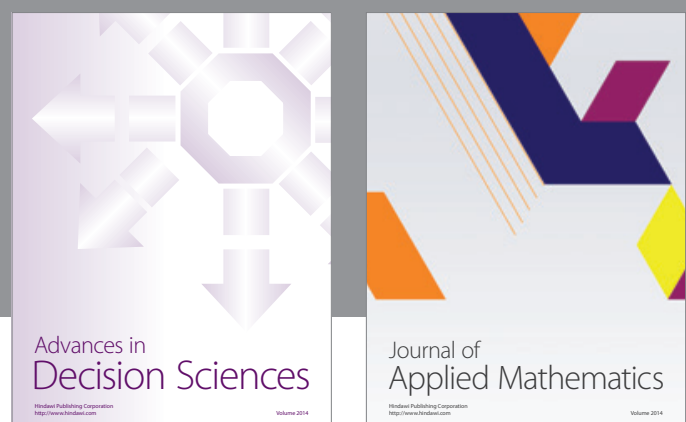

Journal of

Applied Mathematics
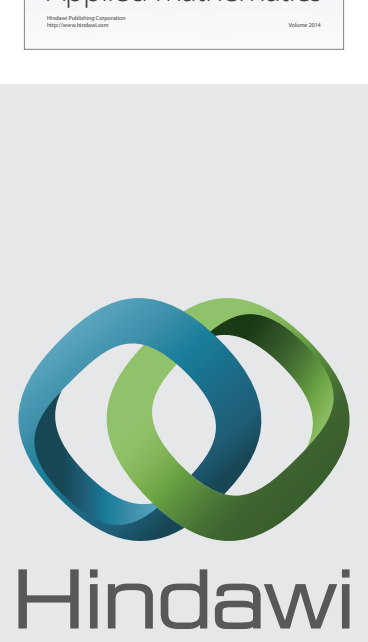

Submit your manuscripts at http://www.hindawi.com
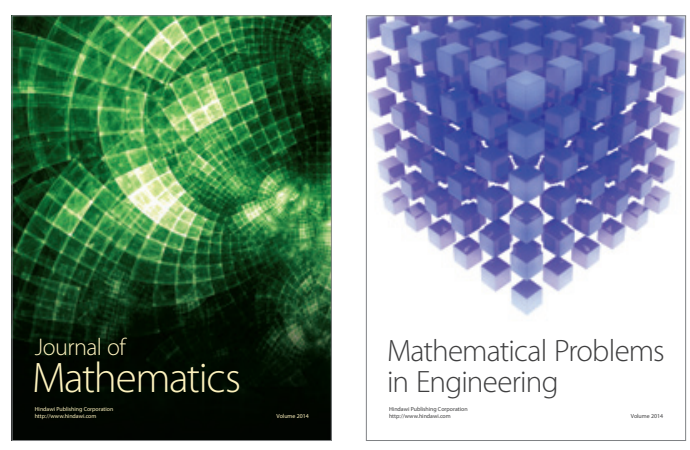

Mathematical Problems in Engineering
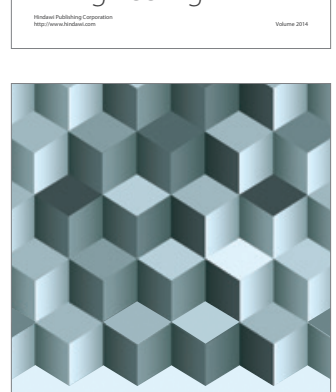

Journal of

Function Spaces
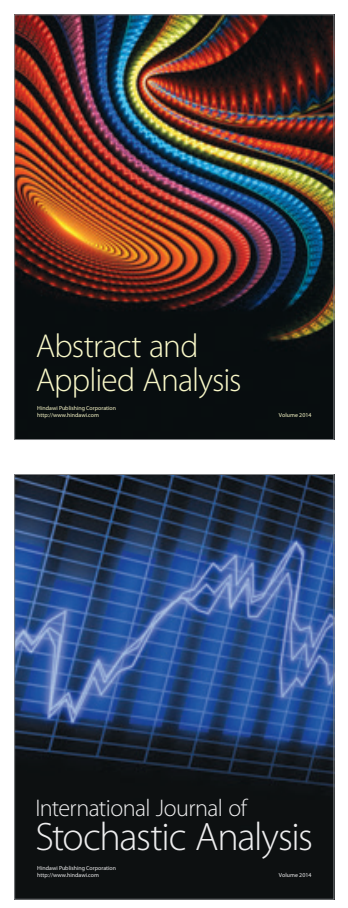

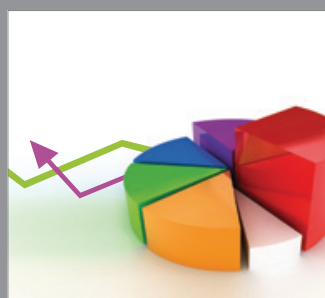

ournal of

Probability and Statistics

Promensencen
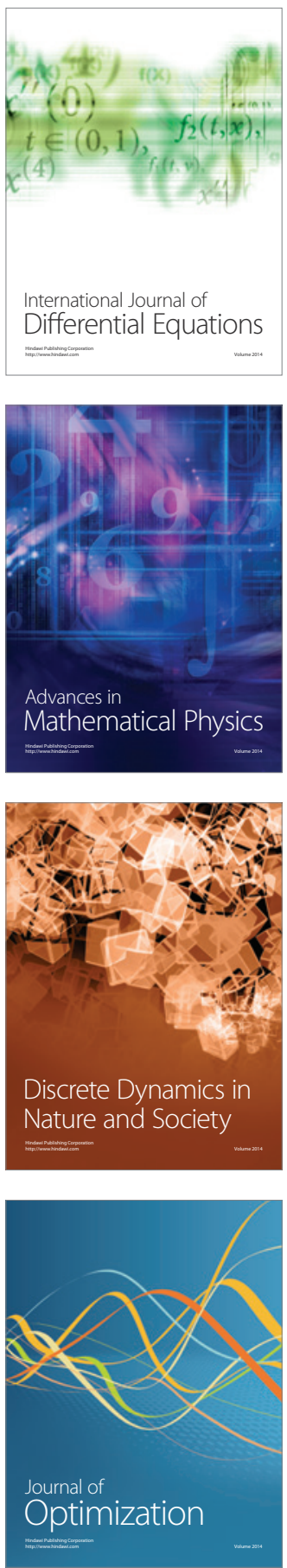